\title{
Two new species of Pedinotus Szépligeti 1902 (Hymenoptera: Braconidae: Doryctinae) from the Savannah in São Paulo state, Brazil
}

\author{
Castro, CS. ${ }^{\mathrm{a} *}$, Nunes, JF. ${ }^{\mathrm{a} *}$ and Penteado-Dias, AM. ${ }^{\mathrm{b} *}$ \\ aPrograma de Pós-graduação em Ecologia e Recursos Naturais, Universidade Federal de São Carlos - UFSCar, \\ Rod. Washington Luís, Km 235, SP-310, CP 676, CEP13565-905, São Carlos, SP, Brazil \\ bDepartamento de Ecologia e Biologia Evolutiva, Universidade Federal de São Carlos - UFSCar, \\ Rod. Washington Luís, Km 235, SP-310, CP 676, CEP13565-905, São Carlos, SP, Brazil \\ *e-mails: clovissormus@hotmail.com, fiorelini@gmail.com, angelica@ufscar.br \\ Received September 10, 2009 - Accepted February 8, 2009 - Distributed November 30, 2010
}

(With 10 figures)

\begin{abstract}
Two new species of Pedinotus genus are described from the Brazilian savannah area, providing a new key to identify the species.
\end{abstract}

Keywords: Braconidae, Doryctinae, Pedinotus, new species.

\section{Duas novas espécies de Pedinotus Szépligeti 1902 (Hymenoptera: Braconidae: Doryctinae) do Cerrado do Estado de São Paulo, Brasil}

\begin{abstract}
Resumo
Duas novas espécies do gênero Pedinotus são descritas para uma área de cerrado e uma nova chave de identificação das espécies é proposta.
\end{abstract}

Palavras-chave: Braconidae, Doryctinae, Pedinotus, novas espécies.

\section{Introduction}

The savannah vegetation is the second Brazilian biome, occupying $21 \%$ of the national territory, where $44 \%$ of the flora is endemic, and so this Brazilian biome is considered the most diverse tropical savannah of the world (Klink and Machado, 2005). The destruction of this ecosystem continues to increase, with $55 \%$ of it having been deforested or changed by humans (Klink and Machado, 2005).

To protect and restore the biodiversity, or even to exploit rationally the resources, it is necessary to improve knowledge about biodiversity (Tundisi and MatsumaraTundisi, 2008). Local estimates that do not consider invertebrates omit most of the biota that they purport to measure, rejecting the segment of fauna that most contributes to the essential processes of the ecosystems (Silva and Brandão, 1999).

Parasitic wasps are important for regulating insect populations, and contribute to the maintenance of ecologic balance in ecosystems.

Doryctinae is one of the most diverse subfamilies of Braconidae (Wharton et al., 1997; Marsh 2002, 2002; Belokobylskij et al., 2004) with almost 1000 described species and roughly 180 recognised genera, of which two thirds are distributed in the Neotropical region (ZaldivarRiverón et al., 2008). This subfamily forms a monophyletic group distinguished by the presence of a row of anterodorsal spines on the fore tibia and a double node in the apex of the ovipositor (Hanson and Gauld, 2006). According to Zaldivar et al. (2008), the subfamily appears as a nonmonophyletic group, based on molecular phylogeny analysis. Despite its high diversity, its biology is scarcely known (Wharton et al., 1997). Most species with their biology already known are idiobionts ectoparasitoids of Coleoptera (Zaldivar-Riverón et al., 2008).

The Pedinotus is a Neotropical genus distinguished by the presence of a semicircular rugose, punctate or carinate area at the base of the second metasomal tergum. It includes 11 species, distributed in seven countries (Felix and Penteado-Dias, 2004; Marsh, 2002), two new species being described in the present paper. In Brazil, the genus has two species recorded (P. brasiliensis and $P$. tundisii). Recently other Ichneumonoidea species from the Neotropical region have been studied and illustrated (Loffredo and Penteado Dias, 2008 a, b; Onody and Penteado-Dias, 2006).

The present paper aims to describe two new species of Pedinotus Szépligeti, both holotypes being captured in Santa Rita do Passa Quatro, São Paulo state, Brazil, by Malaise trap. 
This study is part of a large project covering the richness and diversity of Doryctinae from Savannah areas in São Paulo state, Brazil. Two new species of Pedinotus genus are described from the Brazilian savannah area and a key to identify the species is proposed.

\section{Material and Methods}

The specimens were collected from the Savannah area at the Parque Estadual de Vassununga, 21 ${ }^{\circ} 40^{\prime} 56^{\prime \prime} \mathrm{S}$ and $47^{\circ} 37^{\prime} 13$ " W Santa Rita do Passa Quatro in São Paulo state, Brazil. The genus was identified using Marsh (2002).

The material examined was compared with the holotype of P.tundisii Félix and Penteado-Dias, 2004, to confirm the diagnostic characters of the genus. To compare with the original descriptions of the other species and for sculptures, we used Marsh (2002) and Félix and Penteado-Dias (2004). Specimens are deposited at the DCBU collection (Departamento de Ecologia e Biologia Evolutiva da Universidade Federal de São Carlos, São Carlos, Brazil).

\subsection{Key to Neotropical species of Pedinotus (Modified from Félix and Penteado-Dias, 2004)}

1. Head entirely black and mesosoma entirely orange or red and black

2

- Head either entirely orange or marked with black, at least the eye orbits orange or yellow; colour of mesosoma variable.

....5

2(1). Metasoma black dorsally, yellow laterally and ventrally. columbianus Enderlein, 1912 (Colombia, Panama and Costa Rica)

- Metasoma entirely orange or mostly red........3

3(2). Malar space only rugose; semicircular area of the second tergum slightly smooth or longitudinally carinate

-Malarspace striate andrugose, semicirculararea of the second tergum coarsely punctuate. vassununga sp. n. (Brazil)

4(3). First metasomal tergum with length equal to apical width, completely sculptured; semicircular area on secondtergumlongitudinallycarinate. rojasi Marsh, 2002 (Costa Rica)

-First metasomal tergum longer than apical width, usually completely smooth, semicircular area of the second tergum slightly smooth.

levigatus Marsh, 2002 (Panama and Costa Rica)

5(1). Mesosoma entirely black. ...6

- Mesosoma entirely orange, orange and black or light brown and black.

....8

6(5). First metasomal tergum entirely sculptured ......7

- First metasomal tergum partially or entirely smooth, at least at base; pardalotus Marsh, 2002 (Costa Rica, Honduras and Venezuela)

7(6). First metasomal tergum and median basal semicircular area of the second metasomal tergum rugose or alveolate. niger Marsh, 2002 (Costa Rica)
- First and second terga punctuate; remaining terga smooth, except at base. brasiliensis Szepligeti, 1902 (Brazil)

8(5). Propodeum with distinct areola or nearly so; first metasomal tergum slightly wider at apex than long, second metasomal tergum more than 2.0 times wider at apex than long.............................

- Propodeum without areola; first metasomal tergum longer than apical width; often about equal; second metasomal tergum 1.5 times wider at apex than length.....................tundisii Félix and Penteado-Dias, 2004 (Brazil)

9(8). Sternaulus absent or weakly indicated on anterior half of mesopleuron; propodeum smooth laterally, colour of legs variable .....................10 - Sternaulus complete and scrobiculated, propodeum coarsely punctuate laterally; legs light yellow marked of brown. fasciatus sp. n. (Brazil)

10(9). Propodeum usually entirely orange, occasionally with markings, but rarely black dorsally, often entire body orange, legs rarely black

ferrugineus (Enderlein, 1912) (Southern United States through Northern South America)

- Propodeum usually black, at least always black dorsally, body often black and orange, legs usually black ..variegatus Marsh, 2002 (Costa Rica)

Pedinotus vassununga sp. n.

Female, body length $90 \mathrm{~mm}$.

Colour: Head including antennae black, palpi yellow; mesosoma predominantly black, propodeum and metapleuron red, propleuron and pronotal collar black; metasoma mostly red; ovipositor and sheaths blackish; legs honey yellow, with middle and hind coxae, hind trochanter, trochantelus and all tarsomeres black; basal half of hind femur and apex of hind tibia brown; wings dusky with veins brown and stigma yellow (Figure 1); tegula reddish brown. Head: face with central area smooth and protruding (Figure 2), malar space rugose and vertex striate, frons, gena and temple smooth; malar space 0.3 eye height; ocell-ocular distance 2.5 times the diameter of lateral ocellus; antennae broken with at least 34 antennomeres. Mesosoma: pronotum smooth and polished; pronotal groove impressed, scrobiculate; mesoscutal lobes smooth and polished; notauli scrobiculated, meeting before scutellum in a large rugose area; pré-scutellar sulcus carinate, scutellum slightly punctuate; mesopleuron including subalar groove smooth and polished, sternaulus absent; propodeum smooth laterally, punctuate apico-dorsally, median carina present basally, two apical lateral carinae (Figure 3). Legs: apical lateral tubercle of hind coxa distinct and strongly protruding; fore tibia with a row of five to seven conspicuous anterodorsal spines; middle tibia with row of four to five anterodorsal spines (Figure 4). Wings: Fore wing with vein $1 \mathrm{cu}$-a post-furcal with vein $1 \mathrm{M}$; first subdiscal cell closed at apex, 2cu-a present; hind wing with vein $\mathrm{r}-\mathrm{m} 0.17$ length of vein $1 \mathrm{M} ; \mathrm{M}+\mathrm{CU} 0.3$ length 
of $1 \mathrm{M}$; vein $\mathrm{r}$ present and spectral. Metasoma (Figure 3): first tergum dorsally punctuate and laterally rugose, length equal to apical width; median carina reaching half of the tergum; median semicircular area of second tergum coarsely punctuate, lateral areas of this tergum rugose, third tergum with punctate groove; third and fourth terga scrobiculate; fourth and fifth terga weakly punctate on basal area; ovipositor longer than metasoma.

Material examined. Holotype (DCBU); female, Brazil, SP, Santa Rita do Passa Quatro, Parque Estadual de Vassununga, $21^{\circ} 40$ ' 56" S/ 47 37' 13" W, savannah vegetation, 2.X.2006; A.M.P.Dias col. Paratypes (DCBU): 1 female idem holotype; 3 females, Brazil, SP, Santa Rita do Passa Quatro, Parque Estadual de Vassununga, $21^{\circ} 40^{\prime} 56^{\prime \prime} \mathrm{S}$ and $47^{\circ} 37^{\prime} 13^{\prime} \mathrm{W}$, savannah vegetation,
22.VIII.2007; A.M.P.Dias col.; 1 female, Brazil, SP, Porto Ferreira, Parque Estadual de Porto Ferreira, $22^{\circ} 15^{\prime}$ 57', S/ $47^{\circ} 10^{\prime} 26^{\prime \prime} \mathrm{W}$, savannah vegetation, 10.VII.2006; A.M.P.Dias col.

Comments. This species is distinguished from $P$. rojasi by malar space rugose and striate, mesosoma mostly black, metasoma red dorsally, legs honey yellow, middle leg with coxa black and row of four to five anterodorsal spines on the middle tibia; trochanter and trochantelus black, last tarsomeres black; wings dusky with brown veins; propodeum smooth laterally and punctuate apico-dorsally; semicircular area of second tergum coarsely punctate.

Etymology. The species name refers to Parque Estadual de Vassununga, the collecting place.
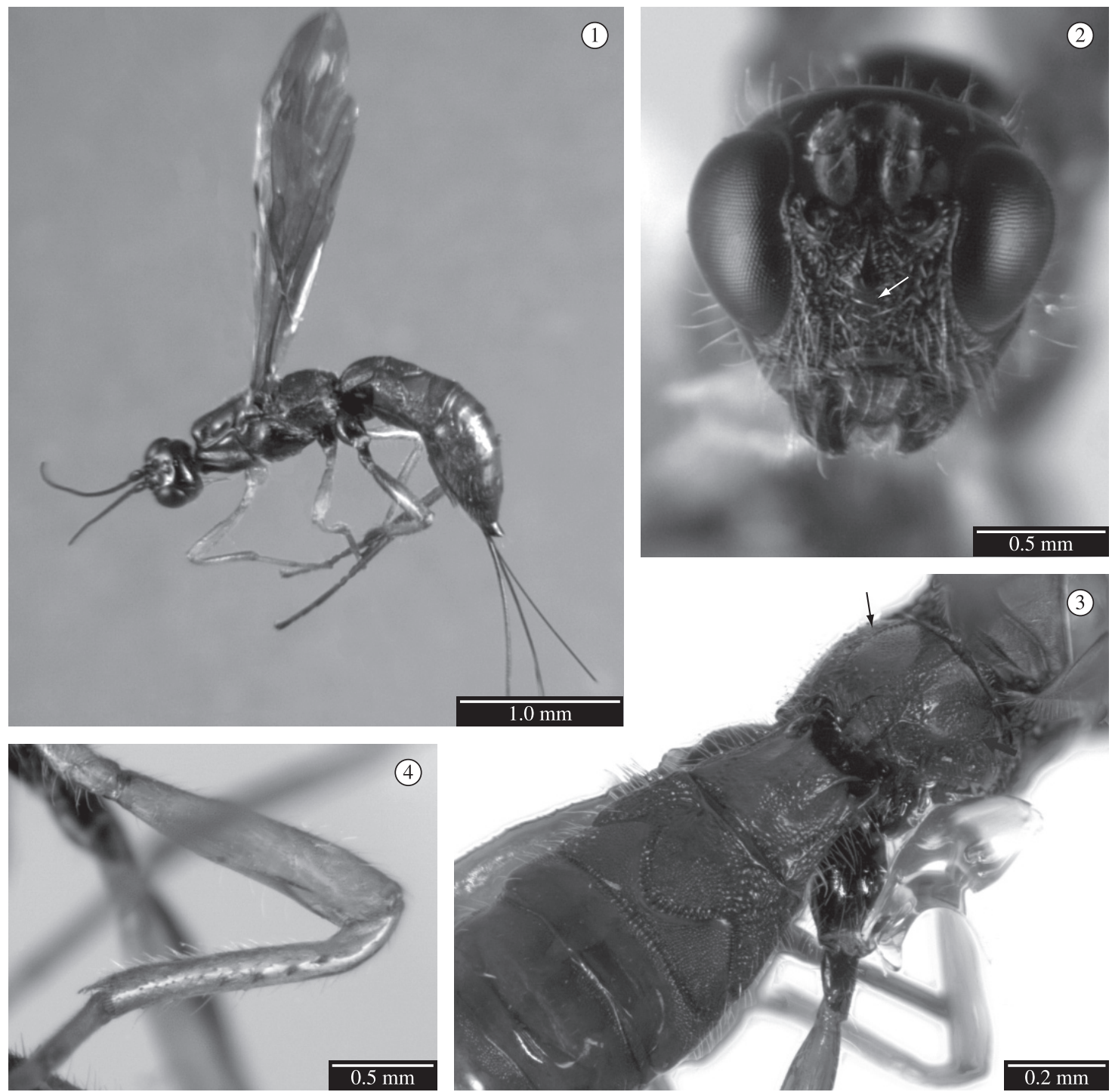

Figures 1-4. Pedinotus vassununga spec. nov. female. 1) habitus, lateral aspect; 2) head with arrow indicating face with central area smooth and protruding; 3 ) propodeum with arrow indicating two apical lateral carinae; metasoma; and 4) middle tibia with arrow indicating a spine. 


\section{Pedinotus fasciatus sp.n.}

Female, body length $60 \mathrm{~mm}$.

Colour: Head with temple and gena yellow, vertex varying from yellow to dark brown, face and malar space yellow, face black only medially, antennae with scape and pedicel yellow with brown stripe laterally, flagellomeres brown, palpi white; mesosoma varying from light to dark brown; metasoma with first tergum black dorsally, remainder terga marked with black and yellow; wings lightly dusky, veins brown and black; stigma dark brown, tegula light yellow; legs light yellow, marked of brown; fore and middle coxae light yellow; hind coxa light brown, trochantellus partially brown, tarsi brownish (Figure 5). Head: face rugose, vertex and temple smooth, frons slightly scavate and transversally striate; malar space 0.3 eye height; ocell-ocular distance twice diameter of lateral ocellus; clypeus smooth,

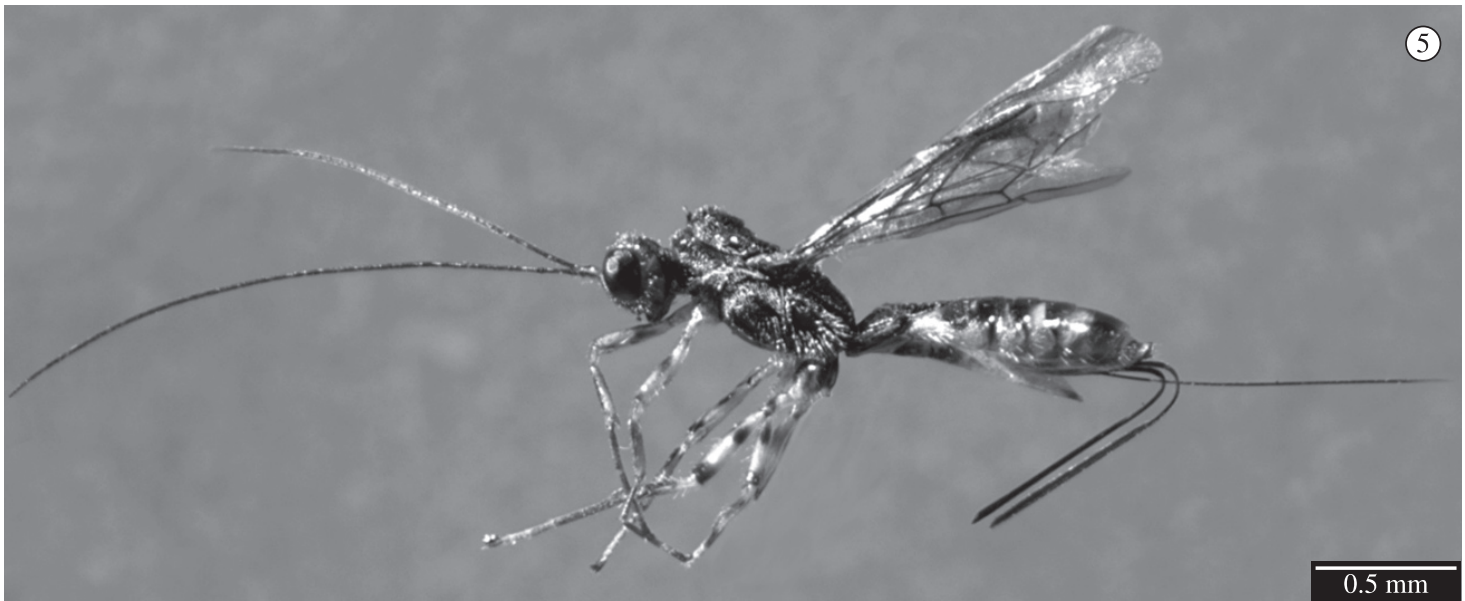

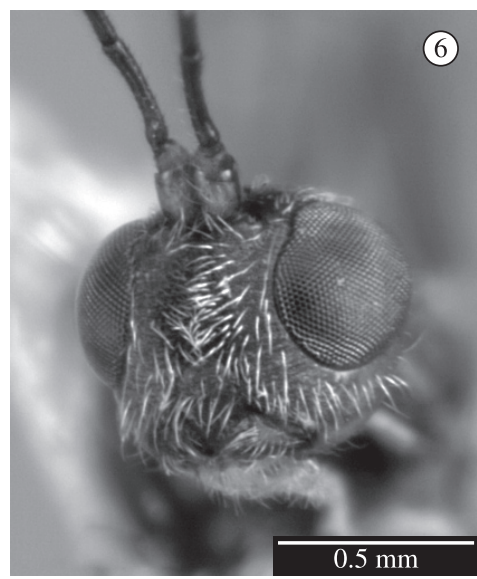

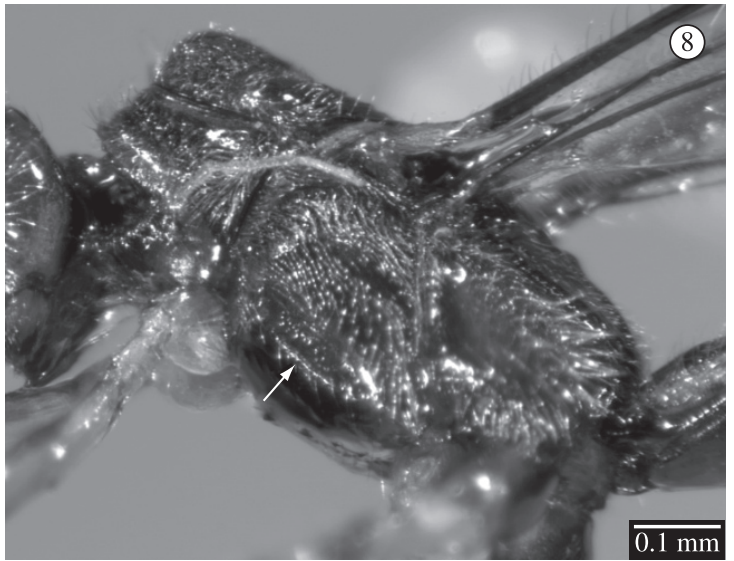

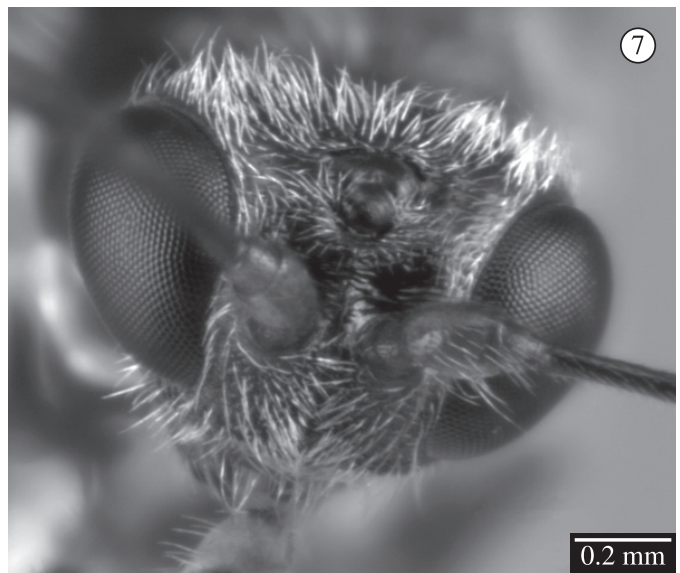
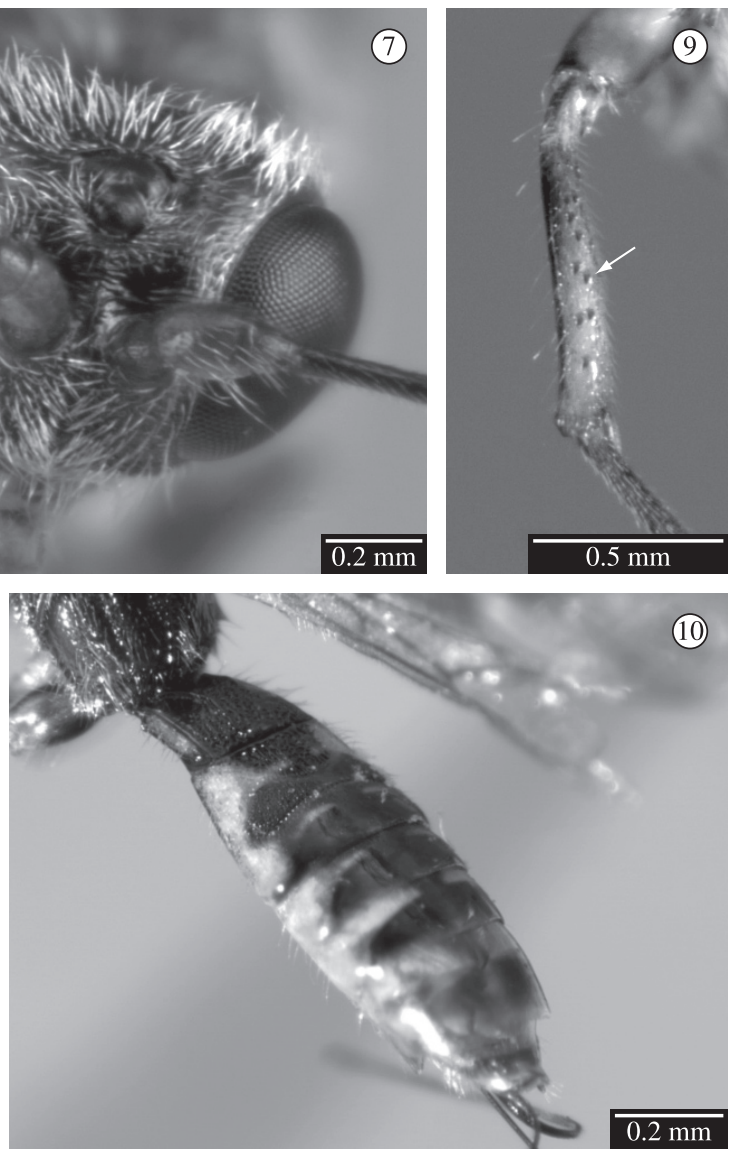

Figures 5-10. Pedinotus fasciatus spec. nov. female. 5) habitus, lateral aspect; 6) head in frontal view; 7) head in dorsal view; 8) mesopleuron with arrow indicating the sternaulus; 9) fore tibia with arrow indicating a spine; 10) metasoma. 
oral opening equal length malar space, 40 antennomeres (Figures 6 and 7). Mesosoma: pronotum smooth, pronotal groove scrobiculate; mesoscutal lobes and pronotal lobes smooth; notauli scrobiculate anteriorly, meeting before scutellum in a rugose carinate area; scutellum smooth; mesopleuron including subalar groove smooth, sternaulus, complete and scrobiculate (Figure 8); propodeum weakly punctuate latero-dorsally, lateral carinae distinct. Legs (Figure 9): hind coxa with antero-dorsal tubercle distinctly protruding; fore tibia with seven to nine anterodorsal spines distributed irregularly; middle tibia with a row of anterodorsal spines on dorsal surface. Wings: fore wing vein 1cu-a post-furcal, first subdiscal cell present; hind wing vein r-m 0.15 length of vein $1 \mathrm{M}$; $\mathrm{M}+\mathrm{CU} 0.35$ length 1M. Metasoma (Figure 10): first tergum carinate, coarsely punctuate, apical width wider than long; second tergum with median semicircular area carinate rugose, finely punctuate, third tergum punctuate, fourth, fifth and sixty terga smooth apically and punctuate on basal area; ovipositor slightly longer than metasoma.

Material examined. Holotype (DCBU); female, Brazil, SP, Santa Rita do Passa Quatro, Parque Estadual de Vassununga, $21^{\circ} 40^{\prime} 56^{\prime}$ 'S/ 47 $37^{\circ} 13^{\prime}$ 'W, savannah vegetation, 29.XII.2006; A.M.P.Dias col. Paratypes (DCBU): 1 female, Brazil, SP, Santa Rita do Passa Quatro, Parque

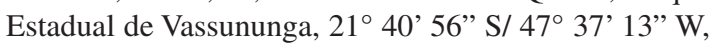
savannah vegetation, 8.X.2007; A.M.P. Dias col. 1 female, Brazil, SP, Estação Ecológica de Bauru, 22 14' 02" S/ 49 05' 19" W, savannah vegetation, 17.X.2006; A.M.P.Dias col.; 1 female, Brazil, SP, Estação Ecológica de Bauru, $22^{\circ}$ 14' 02" S/ 4905' 19" W, savannah vegetation, 28.XI.2006; A.M.P.Dias col.; 1 female, Brazil, SP, Estação Ecológica de Mogi Guaçu, $22^{\circ} 15^{\prime}$ 57' S/ 47 10' 26” W, savannah vegetation, 05.II.2007; A.M.P.Dias col.

Comments. This species is distinguished from $P$. ferrugineus by white palpi, light yellow tegula, light yellow legs with brown marks; sternaulus complete and scrobiculate; propodeum punctate latero-dorsally; fourth, fifth and sixth terga of metasoma punctate on basal area; ovipositor slightly longer than metasoma.

Etymology. The name refers to the colour of the legs of the specimens.

Acknowledgements - We are grateful to CNPq and FAPESP for financial support, to Eduardo Mitio Shimbori for his assistance, to Instituto Florestal do Estado de São Paulo, for permit the collection of material.

\section{References}

BELOKOBYLSKIJ, AS., ZALDIVAR-RIVERÓN, A. and QUICKE, DLJ., 2004. Phylogeny of the genera of the parasitic wasps subfamily Doryctinae (Hymenoptera: Braconidae) based on morphological evidence. Zoological Journal of the Linnean Society, no. 142, p. 369

FÉLIX, FC. and PENTEADO-DIAS, AM., 2004. A new species of Pedinotus (Hymenoptera: Braconidae: Doryctinae) from Brazil. Zootaxa, no. 602, p. 1-4.

HANSON, PE. And GAULD, ID., 2006. Hymenoptera de la región Neotropical. The American Entomological Institute, vol. 77, p. 512.

KLINK, CA. and MACHADO, RB., 2005. A conservação do Cerrado brasileiro. Megadiversidade, vol. 1, no. 1.

LOFFREDO, AP. and PENTEADO-DIAS, AM., 2008a. First record of Schizopyga Gravenhorst (Hymenoptera, Ichneumonidae, Pimplinae) from Brazil and a description of a new species. Brazilizan Journal of Biology, vol. 68, no. 2, p. 457-458.

-, 2008b. First record of Ticapimpla vilmae Gauld, 1991 (Hymenoptera, Ichneumonidae, Pimplinae) from Brazil. Brazilizan Journal of Biology, vol. 68, no. 4, p. 911.

MARSH, PM., 2002. The Doryctinae of Costa Rica (excluding the genus Heterospilus). Memoirs of the American Entomological Institute, vol. 70, p.166.

ONODY, HC. and PENTEADO-DIAS, AM., 2006. Aiura, a new genus of Campopleginae (Hymenoptera: Ichneumonidae) from Brazil. Brazilizan Journal of Biology, vol. 66, no. 2b, p. 755-758.

SILVA, RR. and BRANDÃO, CRF., 1999. Formigas como indicadores da qualidade ambiental e da biodiversidade de outros invertebrados terrestres. Biotemas, vol. 12, no. 2, p. 55-73.

TUNDISI, JG. and MATSUMURA-TUNDISI, T., 2008. Biodiversity in the Neotropics: ecological, economics and social values. Brazilizan Journal of Biology, vol. 68, no. 4, p. 1- 6.

WHARTON, RA., MARSH, PM. and SHARKEY, MJ., 1997. Manual of the new world genera of the family Braconidae (Hymenoptera). Special Publication of the International Society of Hymenopterists, no. 1, p. 207.

ZALDIVAR-RIVERÓN, A., BELOKOBYLSKIJ, SA., LEÓNREGAGNON, V., BRICEÑO GR. and QUICKE, DLJ., 2008. Molecular phylogeny and historical biogeography of the cosmopolitan parasitic wasp subfamily Doryctinae (Hymenoptera: Braconidae). Invertebrate Systematics, no. 22, p. 345. 
